\title{
INVESTIGATED CHARACTERISTICS OF WEAVING SECTIONS FROM FIELD DATA AND DEVELOPED SIMULATION MODEL
}

\author{
Dr. HAMid AthaB Al-JaMeEl \\ Dep. of Civil, University of Kufa-Iraq
}

\begin{abstract}
Weaving sections widely spread among other traffic facilities. Different types of weaving section have been recognized through various editions of Highway Capacity Manual (HCM). However, the HCM has suffered from inability to represent driver behaviour at these sections. Therefore, for each type, there is a specific behaviour. This study has focused on investigating weaving characteristics using more than 60 hours of field data and also MIDAS data have involved. The observed characteristics include merging and diverging points for weaving vehicles, how drivers react to weaving sections in terms of changing their speed, cooperative and aggressive behaviour of drivers and effective length for each type of weaving sections. Seven different sites have been investigated in the UK through this study. The results of this study indicate that the effective length is equal to full weaving length for weaving length less than $300 \mathrm{~m}$ and $200 \mathrm{~m}$ for the weaving length higher than $300 \mathrm{~m}$. Moreover, specific limits for merging and diverging points have been investigated through this study. Then, the simulation model has been developed to find out other characteristics from the simulation model such as applying new effective management by changing weaving section from Type A to Type B with significant increase in the capacity of the new section.
\end{abstract}

KEYWORDS: weaving section, simulation model, driver behavior

\section{INTRODUCTION}

$\mathbf{I}^{\mathrm{t}}$ t has been recently found that the high frequency of lane changing at weaving section is the main factor that affects on the capacity of this section due to disturbance of traffic (Al-Jameel, 2011). The relevant literature indicates evidence about the concentration of lane changing activities close to the beginning of the weaving section within moderate to heavy flow (Kwon et al., 2000). Wherefore, the effective operational strategies depend mainly on understanding the traffic behaviour at weaving sections.

Based on the conclusions found by Lee and Cassidy(2009), regrettably, there is an obvious lack in the weaving field data. Consquently, there is a vage for information relating to the speed whether under the traffic status congestion or non-congestion and before bottleneck or after bottleneck.

Therefore, the motivation behind this study is to dissect in details the factors affecting traffic behaviour at weaving sections from seven different sites and using collected data in order to calibrate and validate the developed simulation model. Then, test other behaviours by that model.

\section{WEAVING SECTION}

A great amount of literature-based evidence is found regarding the influence of factors affecting the capacity of weaving section such as class of weaving section (see Figure 1), weaving ratio, volume ratio length and width for the weaving section and the speed for non-weaving and weaving vehicles (Lertworawanich and Elefteriadou, 2003).

Taking into account the factors above, the HCM 2000 defines the weaving volume as the total traffic volume serving by a weaving section. In addition, the weaving ratio could be defined as the small weaving volume from one direction to the total weaving. In addition, the HCM 2000 specify 0.5 as a maximum value for weaving ratio under high turbulence or high interaction between traffic streams during heavy flow approaching from capacity (Fazio and Rouphail, 1990). 


\section{I-Type A}

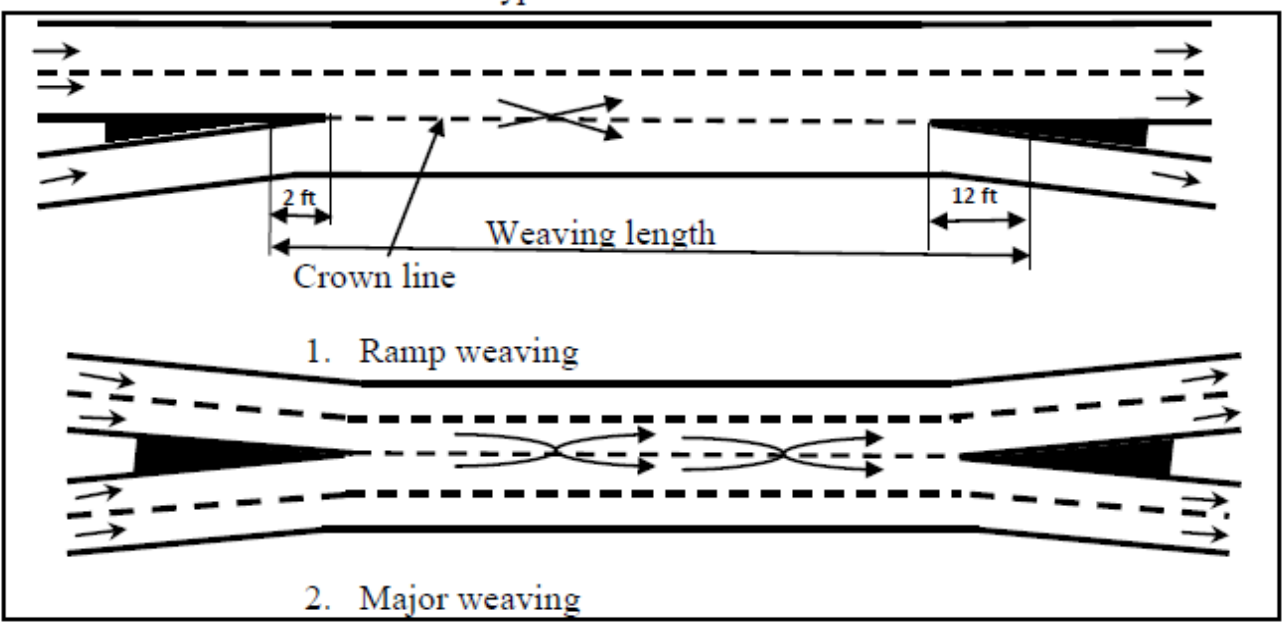

II-Type B

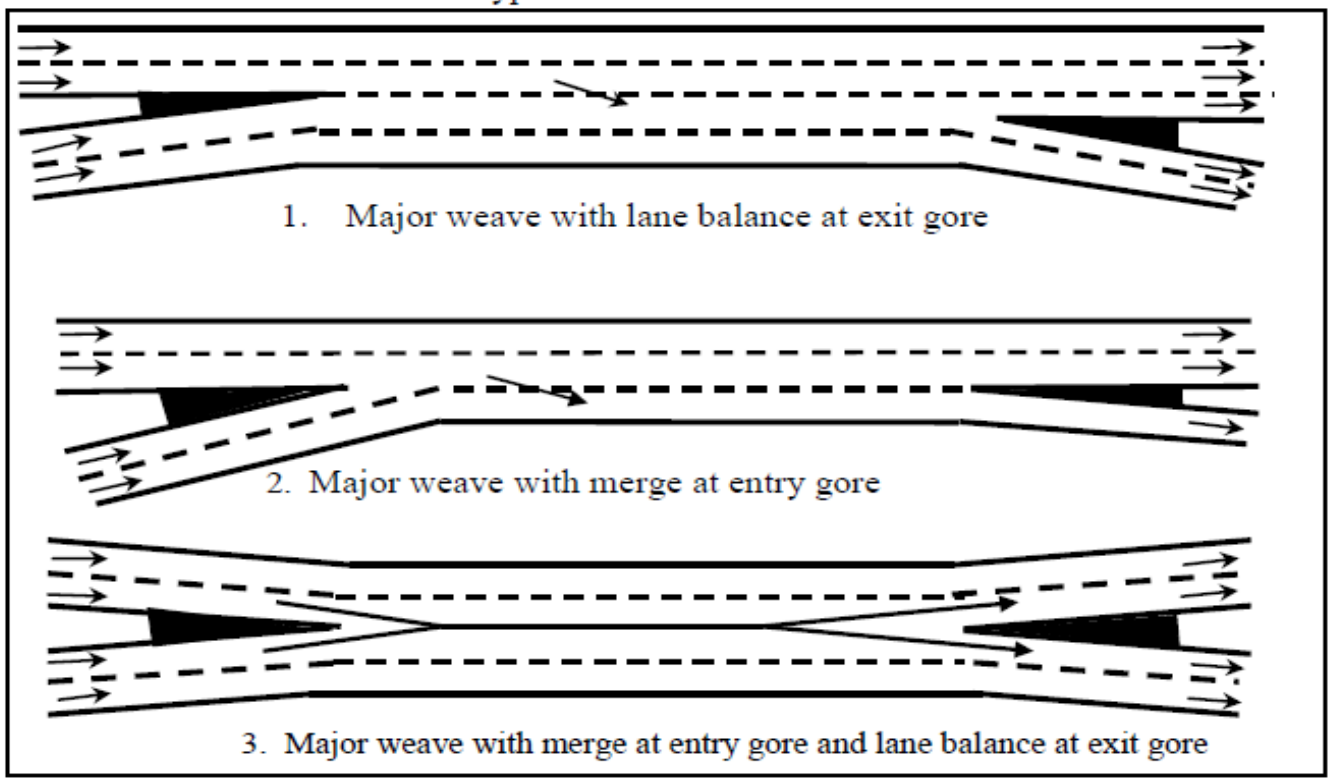

III- Type C

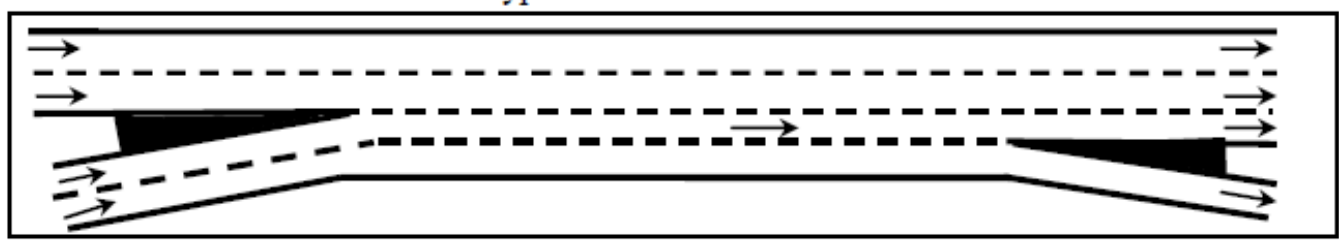

Fig. (1): Types of weaving sections (adapted from the HCM 2000).

\section{DRIVER BEHAVIOR}

Having reported that, in the previous section, geometric design and traffic characteristic have an effect on the weaving capacity. Drivers' behaviour has also a direct impact on the weaving capacity as reported by Lee and Cassidy (2009). The authors demonstrated that, unfortunately, the reason of triggering bottleneck activation was not determined by most previous studies because these studies did not use field traffic data to investigate such factor. On the other hand, the bottleneck activation was associated with flow discharge reduction as noted by Bertini and Malik (2004). This was attributed by the authors for the conflicting merging and diverging vehicles at on-ramp. Moreover, they also reported that following drops in on-ramp flow consistently 
synchronize with bottleneck activations, and estimated that these reductions in on-ramp flows were obliged by queues on the motorway caused by those diverging drivers.

In contrast with what Bertini and Malik (2004) have found, Lee and Cassidy (2009) demonstrated from the same data used by Bertini and Malik that there was no connection between the on-ramp flow with bottleneck activation because the demand flow for on-ramp were only around 200 $\mathrm{veh} / \mathrm{hr}$ immediately prior to the activation of bottleneck. This too low flow was not responsible of the congestion.

\section{WEAVING LENGTH}

To achieve manoeuvring along weaving section, there is a need for a certain length. Different methods have been used to determine such required length, the Design Manual for Roads and Bridges (2010) in the UK suggested that this length depending on weaving volume, total volume and design speed. Whereas, Vermijs and Schuurman (1994) found that the required length for implementing most lane changes for Type A ramp weave was the first $350 \mathrm{~m}$ from the merge gore area of the weaving section.

\section{RESEARCH METHODOLOGY}

This study has focused on collecting data from various locations within the Manchester city. These data have been dissected in depth along the weaving section and even at upstream to capture the traffic characteristics for developing a microsimulation model.

The sources of the collected data are video camera and Motorway Incident Detection and Automated Signalling (MIDAS) data. The reason behind using a video camera is that some characteristics such as the cooperative and yielding behaviour could not be collected by other means. However, the data collected by a video camera consuming time in analysis data such as gaps, relative speed and frequency of lane changes.

\subsection{Selection of sites}

Selecting the suitable site is a vital point in each study. Different sites have been visited within the Greater Manchester Area and then just seven sites have been chosen in order to satisfy the variation in geometric designs and type of flow. Table 1 and Figure 2 indicate the number of visits, duration and layouts.

\subsection{Data collection}

It was a difficult task to determine the flow, the number of lane changes (LC) and vehicle classification. The duration of flow was 5minutes. These data have been analysed by playback on the computer monitor screen to extract the required characteristics using an event recorder (i.e. recording the time and counts when certain vehicles cross the screen line). The location of merging points and lane changing have been determined from the same method of playback video.

Table (1): Information about the visits to weaving section sites.

\begin{tabular}{|c|c|c|c|c|}
\hline Section & Site & Dir. & Date & Description \\
\hline Mancunian Way Site 1. See Figure 2. & $\begin{array}{l}\text { At the Eastern part of the } \\
\text { Mancunian Way near } \\
\text { MMU. }\end{array}$ & WB & $\begin{array}{l}\text { Most recordings started at } \\
8 \text { am and ended at } 5 \text { pm. } 12 \\
\text { visits were made. }\end{array}$ & $\begin{array}{l}28 \text { hours observed during } \\
\text { different days/months. }\end{array}$ \\
\hline $\begin{array}{l}\text { Mancunian Way Site 2-Section 1. See } \\
\text { Figure } 2 \text {. }\end{array}$ & $\begin{array}{l}\text { At the western part of the } \\
\text { Mancunian Way }\end{array}$ & WB & $23^{\text {th }}$ of July, 2009. & 4 hours for evening peak \\
\hline $\begin{array}{l}\text { Mancunian Way Site 2-Section 2. See } \\
\text { Figure } 2 .\end{array}$ & $\begin{array}{l}\text { At the western part of the } \\
\text { Mancunian Way }\end{array}$ & $\mathrm{EB}$ & $23^{\text {th }}$ of July, 2009. & 5 hours for evening peak \\
\hline M60-J2 Section 1. See Figure 2. & $\begin{array}{l}\text { Between Junctions } 2 \text { and } \\
3\end{array}$ & WB & $\begin{array}{l}15^{\text {th }} \text { of March, and } 8^{\text {th }} \text { of } \\
\text { October, } 2010 .\end{array}$ & $\begin{array}{l}4 \text { hours at A.M peak. } \\
2 \text { hours at P.M peak. }\end{array}$ \\
\hline M60-J2 Section 2. See Figure 2. & $\begin{array}{l}\text { Between Junctions } 2 \text { and } \\
3\end{array}$ & $\mathrm{~EB}$ & $\begin{array}{l}\text { Monday, } 15^{\text {th }} \text { of March, } 8^{\text {th }} \text { of } \\
\text { October, and } 28^{\text {th }} \text { of October } \\
2010 \text {. } \\
11^{\text {th }} \text { of May, } 2011 .\end{array}$ & $\begin{array}{l}7 \text { hours for morning and } 5 \\
\text { hours evening peaks. } \\
6 \text { hours from morning till } \\
\text { evening. }\end{array}$ \\
\hline $\begin{array}{l}\text { Northenden (A5108)-Section 1. See Figure } \\
2 .\end{array}$ & Within Northenden & SB & $\begin{array}{l}28^{\text {th }} \text { of June and } 2^{\text {nd }} \text { of July, } \\
2010 .\end{array}$ & $\begin{array}{l}2 \text { hours for morning and } \\
\text { evening peaks. }\end{array}$ \\
\hline $\begin{array}{l}\text { Northenden (A5108)-Section } 2 . \quad \text { See } \\
\text { Figure } 2 .\end{array}$ & Within Northenden & NB & $\begin{array}{l}28^{\text {th }} \text { of June and } 2^{\text {nd }} \text { of July, } \\
2010 .\end{array}$ & $\begin{array}{l}2 \text { hours for morning and } \\
\text { evening peaks. }\end{array}$ \\
\hline
\end{tabular}

Dir.: Direction; EB: Eastbound; NB:Northbound; SB: Southbound; WB: Westbound. 


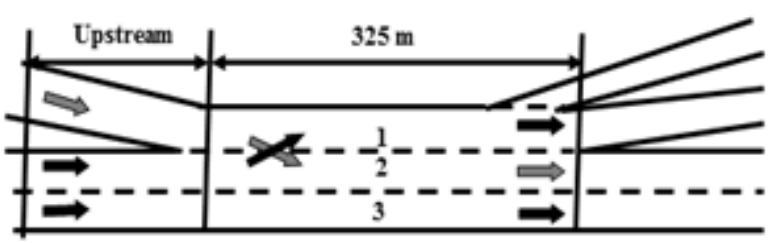

(A) Mancunian Way Site 1

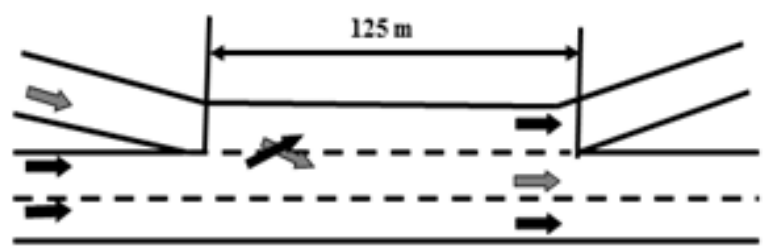

(C) Mancunian Way Site 2-Section 2.

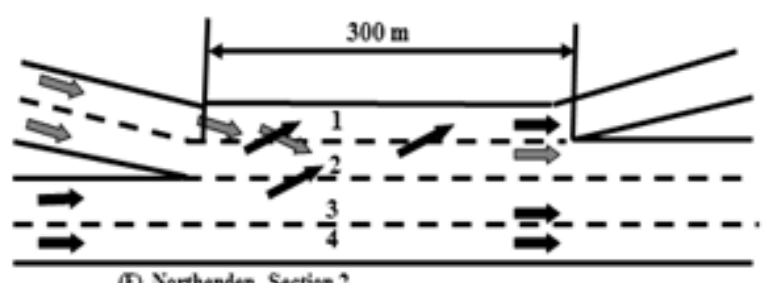

(E) Northenden Section 2

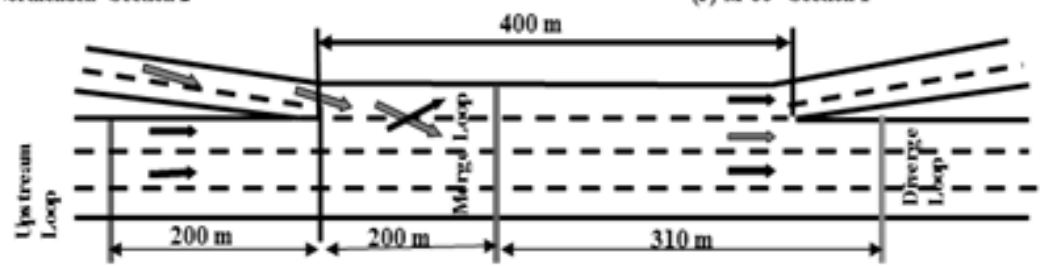

(G) M60-Section 2

Fig. (2): Layouts of seven weaving sections throughout Greater Manchester.

\subsubsection{Upstream characteristics}

At upstream of weaving sections, data for the segregation vehicles from motorway to ramp for Mancunian Site 1 is about $95 \%$ whereas this percentage is $85 \%$ for Northenden Section 2. This is attributed that the first site has $900 \mathrm{~m}$ as separation distance between that section and the close intersection at the upstream whereas the distance is $350 \mathrm{~m}$ for Northenden Section 2. The segregation has been conducted for some sites due to the difficulty of getting vantage points. The proportion of the segregation vehicles from diverging vehicles within the $250 \mathrm{~m}$ upstream for the Mancunian Way site 1 was $70 \%$, whereas the Northenden site 1 was $75 \%$. While the percentage of non-weaving vehicles staying in the shoulder lane after entering weaving section (Mancunian Site 1) was from $40 \%$ to $60 \%$ which is different from $60 \%$ to $80 \%$ mentioned by Pignataro et al. (1975).

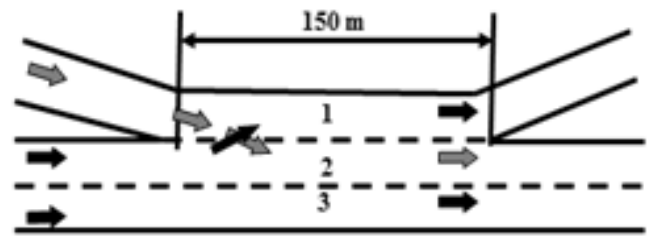

(B) Mancunian Way Site 2-section 1.

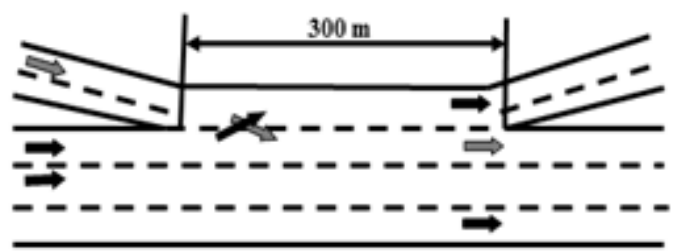

(D) Northenden Section 1

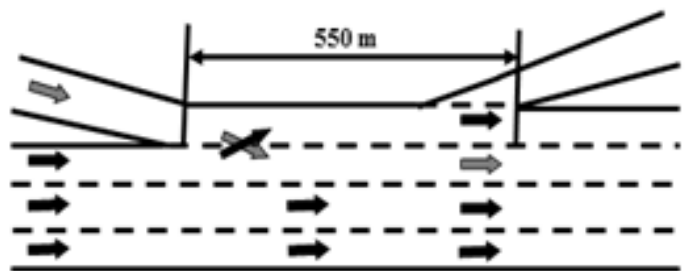

(F) M 60-Section 1

\subsubsection{Frequency of Lane Changes (FLC)}

Weaving sections are characterised by high lane changes which lead to higher frictions and turbulences in the traffic stream than normal sections(Zarean and Nemeth, 1988). The high lane changes in weaving sections represent the higher turbulence and lower capacity than normal sections (Cassidy and May, 1991). Consequently, the frequency of lane changes (FLC) was collected from all sites understudy. In doing so, the maximum FLC between lane 1 and 2 for $76 \mathrm{~m}$ was found $1500 \mathrm{LC} / \mathrm{hr}$ for the Mancunia Way Site as shown in Table 2. This value is in contradiction with the same data collected from the same section characteristics conducted by Cassidy and May (1991) which had value of $1200 \mathrm{LC} / \mathrm{hr}$. Another important observation is that when flow increase, the highest value of lane changes is close to the entrance of weaving section resulting in forming platoons of vehicles. This leads to long queue and vehicles come to fully stop. 
The FLC $/ \mathrm{hr} / \mathrm{km}$ was used as indicator to demonstrate the performance for non-motorway weaving section. This could be classified according to FLC $/ \mathrm{hr} / \mathrm{km}$ as unconstrained $(<1863)$, constrained (1863-3726), and undesirable (>3726) (Fredericksen and Michael, 1994).

Additionally, the Mancunian Way Site 2 Section 1 represents a non-motorway weaving section because of its lower speed limits (i.e. $50 \mathrm{mph}$ ) and the close proximity of several intersections in a relatively short distance.
In spite of the fact that the FLC in this location go beyond the undesirable conditions announced by Fredericksen and Michael (1994), field observations recommend that traffic operation could still be considered as desirable. Subsequently, the criteria utilized by those authors may not be deemed as an effective tool to determine the operational performance of traffic for the weaving section. This could be resulted from the initial length (weaving length) utilized in determining the equivalent FLC per $\mathrm{km}$.

Table (2 ):FLC with different ranges of flow for some weaving sites.

\begin{tabular}{llll}
\hline Section & $\begin{array}{l}\text { Maximum FLC } \\
\text { LC/hr/km }\end{array}$ & $\begin{array}{l}\text { Maximum FLC } \\
\text { LC/hr/length of section }\end{array}$ & $\begin{array}{l}\text { Range of flow } \\
\text { veh/hr }\end{array}$ \\
\hline Mancunian Way Site 1 & 4615 & $1500 \mathrm{FLC} / \mathrm{hr} / 100 \mathrm{~m}$ & From 1100 to 4050 \\
\hline Mancunian Way Site 2-Section 1 & 10800 & $1620 \mathrm{FLC} / \mathrm{hr} / 150 \mathrm{~m}$ & From 2000 to 3500 \\
\hline Mancunian Way Site 2-Section 2 & 4800 & $600 \mathrm{FLC} / \mathrm{hr} / 125 \mathrm{~m}$ & From 2000 to 3000 \\
\hline Northenden Site 1 & & $2316 \mathrm{FLC} / \mathrm{hr} / 300 \mathrm{~m}$ & From 2900 to 5000 \\
\hline Northenden Site 2 & 7720 & $2450 \mathrm{FLC} / \mathrm{hr} / 300 \mathrm{~m}$ & From 4000 to 5600 \\
\hline M60 J 2 Site 1 & 8333 & $1800 \mathrm{FLC} / \mathrm{hr} / 500 \mathrm{~m}$ & From 5000 to 8000 \\
\hline M60 J 2 Site 2 & 3600 & $2172 \mathrm{FLC} / \mathrm{hr} / 420 \mathrm{~m}$ & From 4200 to 7260 \\
\hline
\end{tabular}

\subsubsection{Effective length}

The new parameter suggested by this study is the effective length. It could be defined as the actual length at which most weaving vehicles finishing their necessary LCs in order to reach their destination lane with the weaving section. It was found that the effective length represent the total weaving length (i.e. $150,125 \mathrm{~m}$ for Sections 1 and 2, respectively) for the Mancunian Way Site 2. While, the effective length is around $200 \mathrm{~m}$ for all other ramp weave sections where the actual weaving length is equal or more than $300 \mathrm{~m}$.

\subsubsection{Merging points}

Another factor has been investigated through this study called merging point which indicated the points of crossing the longitudinal pavement marking by vehicles to change from its current lane to the next one. Three hours of field data have been observed under heavy flow to analyse the drivers' behaviour for M60 J2 weaving section. The first $200 \mathrm{~m}$ has been classified as 4 zones each $50 \mathrm{~m}$ for the fact revealed by this study that concentration of $\mathrm{LC}$ at this first section.

The merging points could be divided into two types: First type from lane 1 to 2 and second type from lane 2 to 1 . First type is demonstrated in Figure 3 which shows that the maximum proportions of LC happened within the zone of 0$50 \mathrm{~m}$. This proportion ranges from $39 \%$ to $60 \%$ under moderate to heavy of flow. This proportion oscillates under various level of flow. Nevertheless, this zone indicates the zone of the highest FLC along the weaving section. The $3^{\text {rd }}$ zone has the higher values than the $1^{\text {st }}$ and $4^{\text {th }}$ zone but less than the $2^{\text {nd }}$ zone. This means the highest number of merging vehicles within the first $100 \mathrm{~m}$ ranges from $72 \%$ to $98 \%$ from the vehicles that merging from the first lane. 


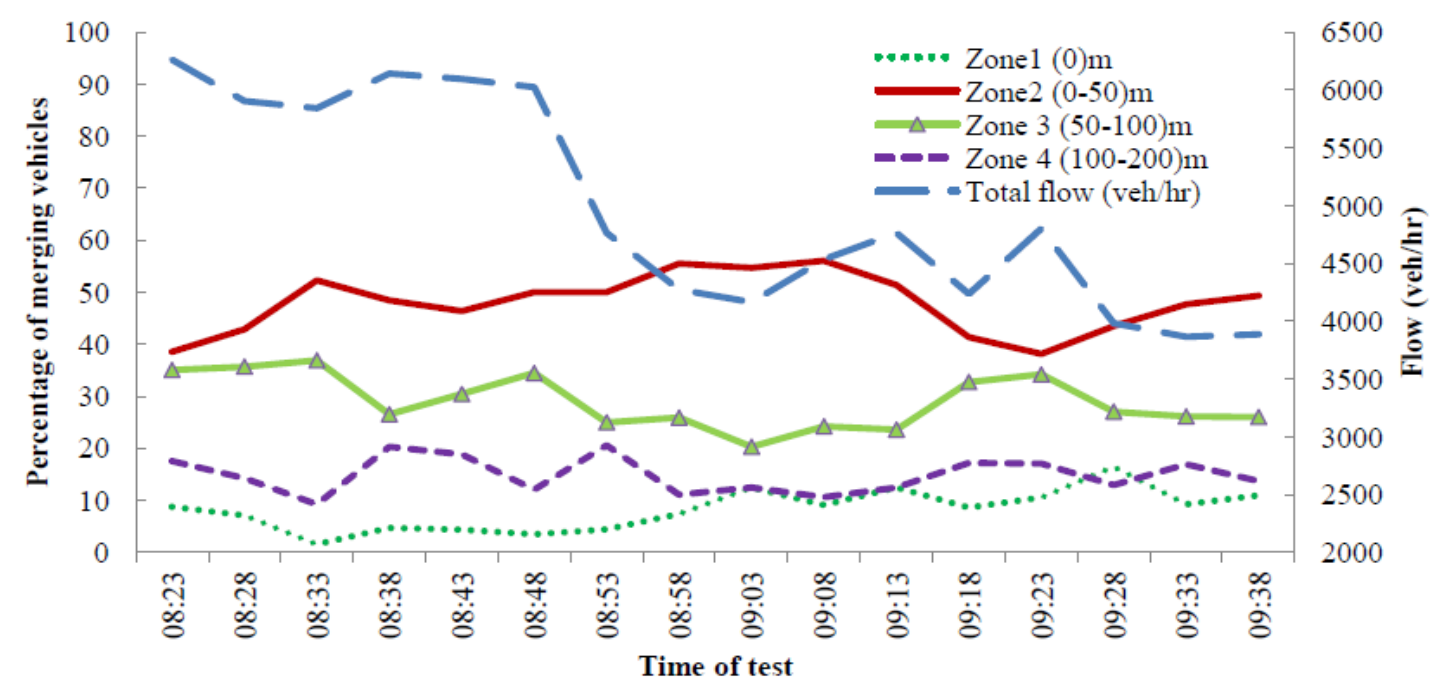

Fig. (3): Proportion of merging vehicles at various zones from the M60-J2 weaving section.

Figure 4 demonstrates the $2^{\text {nd }}$ case. The $2^{\text {nd }}$ zone here also indicates the maximum proportion of concentration among other zones but with larger values than the $2^{\text {nd }}$ zone in the $1^{\text {st }}$ case. Whilst, the values of $1^{\text {st }}$ zone is also larger than values of the $1^{\text {st }}$ zone in the first case by two times or more in some cases as illustrated in Figure 4 . The highest value of merging activities in the $3^{\text {rd }}$ and $4^{\text {th }}$ zones are less that for the same zones is the first case as stated in Figure 4.

Referring to the above, the highest value of merging activities is located in the first $50 \mathrm{~m}$ from the weaving length which may attain $70 \%$ from all merging cases along this section. Then, the proportion of merging vehicles from the $3^{\text {rd }}$ and $4^{\text {th }}$ zones less than $50 \%$ under various level of flow as indicated in Figure 3. Lastly, the results gaining from the merging points indicate that the behaviour of weaving vehicles can be characterised by staying on-ramp vehicles longer distance before entering motorway than motorway vehicles heading to off-ramp.

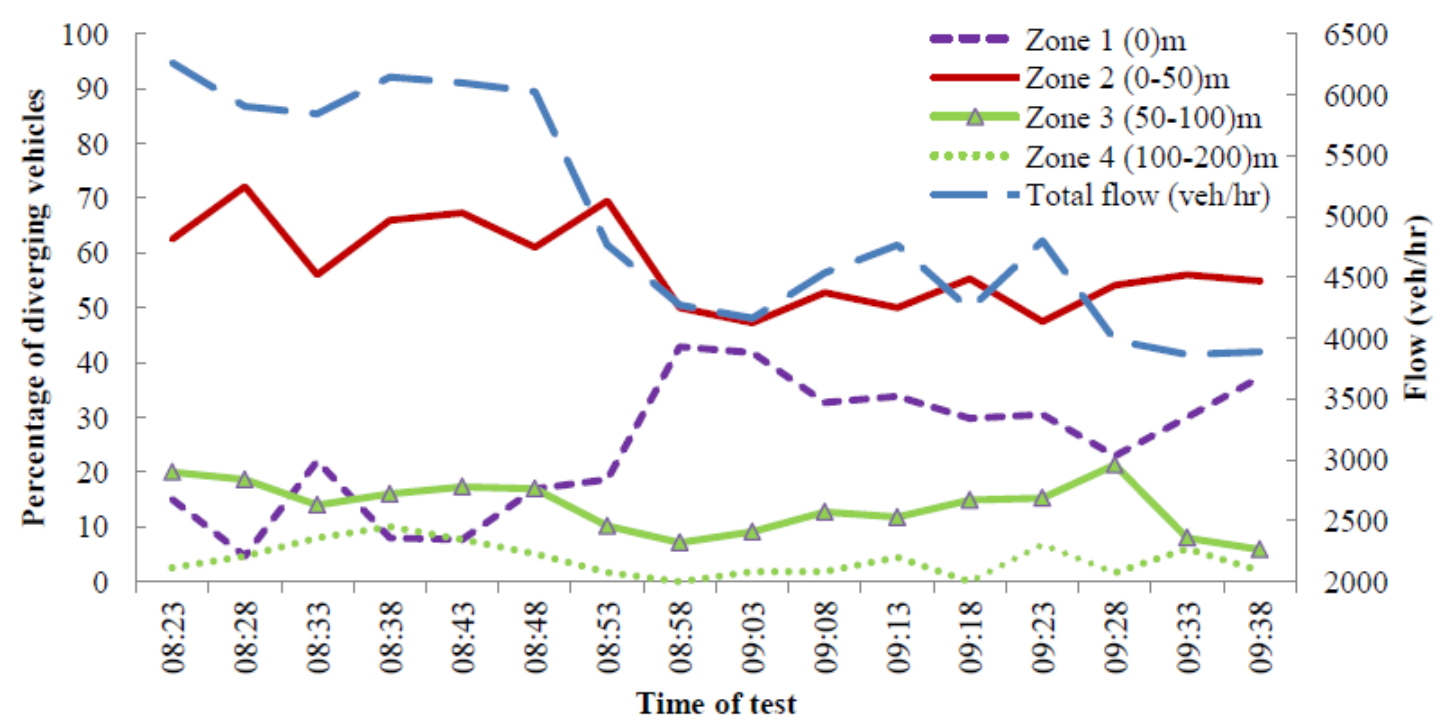

Fig.(4): Proportion of diverging vehicles at various zones of M60-J2 weaving section.

\subsubsection{Bottleneck location}

Knowing bottleneck locations in any part of a motorway was considered by different studies because of their influence on interpreting the causes of congestion and selecting suitable management techniques. Therefore, the location of 
a bottleneck in a weaving section has been investigated depending on field observations and MIDAS data.

Data taken from M60-J2 Section 2 has been used for this analysis. This data was taken from loop detectors located at about 200m (taken from Google Earth and MIDAS map) from both upstream and downstream of the entrance point. Table 3 shows data of flow and speed from both the upstream and downstream loop detectors for the M60-J2 Section 2. The data illustrates that there is a reduction in speed at the upstream section compared with those of the downstream location for all the selected dates. This reduction is generally more than $20 \mathrm{~km} / \mathrm{hr}$. This could be explained by the presence of a traffic bottleneck close to the entrance of the weaving section. This reduction is a sign of bottleneck as reported by Hounsell and McDonald

(1992).

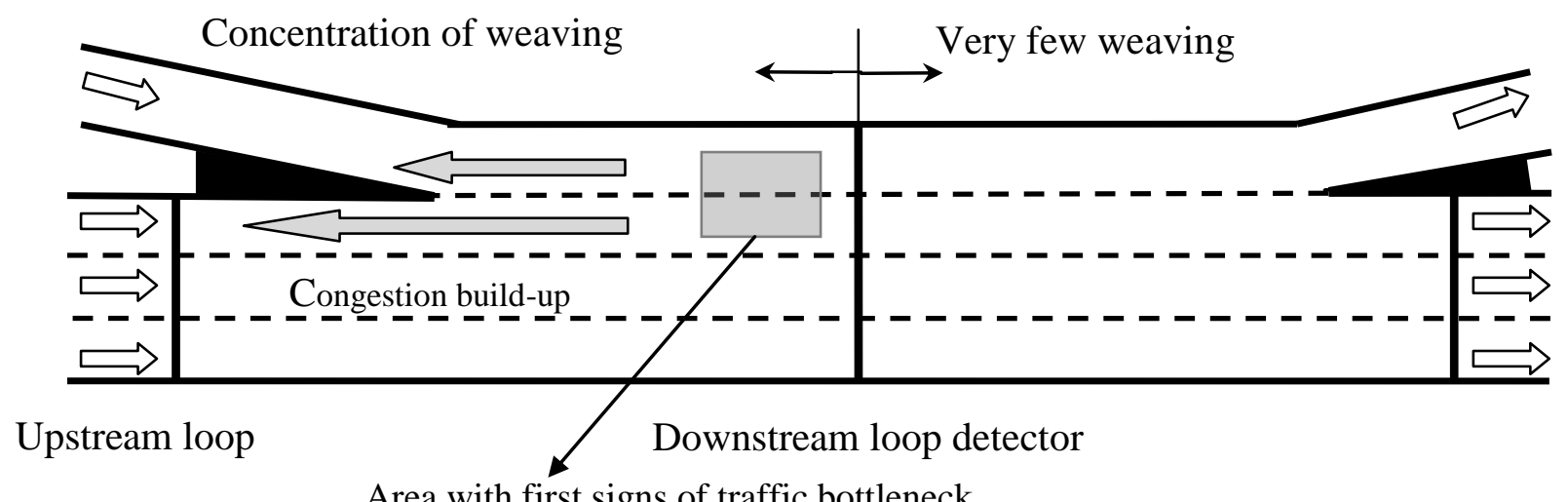

Area with first signs of traffic bottleneck

Fig. (5): Bottleneck locations for the M60 J2 weaving section.

Based on video recordings for the M60 J2 Site 2 during the evening peak hour on 29/10/2010 between 4:30 and 5:30 p.m., the location of the bottleneck is about $70 \mathrm{~m}$ downstream of the entrance point (nose) as indicated by Figure 5.
This could be attributed to the high interaction between merging and diverging vehicles within the upstream segment as discussed in the previous section.

Table (3): Flow and speed for up and downstream loop detectors for the M60-J2 Section 2.

\begin{tabular}{ccccc}
\hline Date & $\begin{array}{c}\text { Time } \\
\text { period }\end{array}$ & Duration & $\begin{array}{c}\text { Upstream detector-flow and } \\
\text { speed }\end{array}$ & $\begin{array}{c}\text { Downstream detector-flow and } \\
\text { speed }\end{array}$ \\
\hline $3 / 3 / 2010$ & $6: 15 \mathrm{p.m}$ & $(5: 55-6: 15)$ & $5508 \mathrm{veh} / \mathrm{hr}(50.6 \mathrm{~km} / \mathrm{hr})$ & $6732 \mathrm{veh} / \mathrm{hr}(69.75 \mathrm{~km} / \mathrm{hr})$ \\
\hline $5 / 3 / 2010$ & $5: 25 \mathrm{p.m}$ & $(5: 15-5: 40)$ & $5244 \mathrm{veh} / \mathrm{hr}(46.5 \mathrm{~km} / \mathrm{hr})$ & $6300 \mathrm{veh} / \mathrm{hr}(72.8 \mathrm{~km} / \mathrm{hr})$ \\
\hline $1 / 4 / 2010$ & $4: 46 \mathrm{p.m}$ & $(4: 21-5: 16)$ & $5124 \mathrm{veh} / \mathrm{hr}(44 \mathrm{~km} / \mathrm{hr})$ & $6216 \mathrm{veh} / \mathrm{hr}(67.0 \mathrm{~km} / \mathrm{hr})$ \\
\hline $7 / 4 / 2010$ & $4: 43 \mathrm{p.m}$ & $(4: 38-4: 53)$ & $5592 \mathrm{veh} / \mathrm{hr}(44 \mathrm{~km} / \mathrm{hr})$ & $7044 \mathrm{veh} / \mathrm{hr}(71.12 \mathrm{~km} / \mathrm{hr})$ \\
\hline
\end{tabular}

In conclusion, the location of bottleneck could start at about $70 \mathrm{~m}$ and oscillate between this location and the entrance point of the merge section. However, the upstream section, especially the $250 \mathrm{~m}$ from the entrance point, suffers from high turbulence and the queues dominate this section.

\section{DEVELOPED SIMULATION MODEL}

The simulation model has been developed by developing other sub-models (car-following, gap acceptance and lane changing). Then, the weaving behaviour will be added to improve the behaviour of the developed model. Visual Compact Fortran has been adopted in developing the model. 


\subsection{Car-following rules}

The longitudinal movement of vehicles in a certain lane has been expressed by the sub-model developed by Al-Jameel (2009). Then, this developed model has been calibrated with observed data reported by Panwia and Dia (2005). This data represents a trajectory data for $300 \mathrm{sec}$ for more details see Al-Jameel (2010).

\subsection{Lane changing rules}

Another important sub-model for building simulation model is the lane changing model. This model is responsible of changing vehicle from current lane to the adjacent one. Based on the literature, there are two types of lane changes namely discretionary and mandatory. A drive carried out the discretionary lane changes when he/she has a desire to increase her/his speed or to avoid being locked behind slower vehicles (Sultan and McDonald, 2001). While mandatory lane changes are implemented to reach the destination.

Figure 6 indicates how the simulated data have been compared with the field data collected by Yousif (1993) and Sparman (1979). These data were mainly collected from two lane normal sections. The simulated data show a reasonable behaviour to mimic the reality in terms of FLC. The figure indicates as the flow increases up to $2000 \mathrm{veh} / \mathrm{hr}$, the FLC reaches the maximum value. Then, as flow increases the FLC decreases due to lack of available gaps to conduct the lane changing manoeuvres.

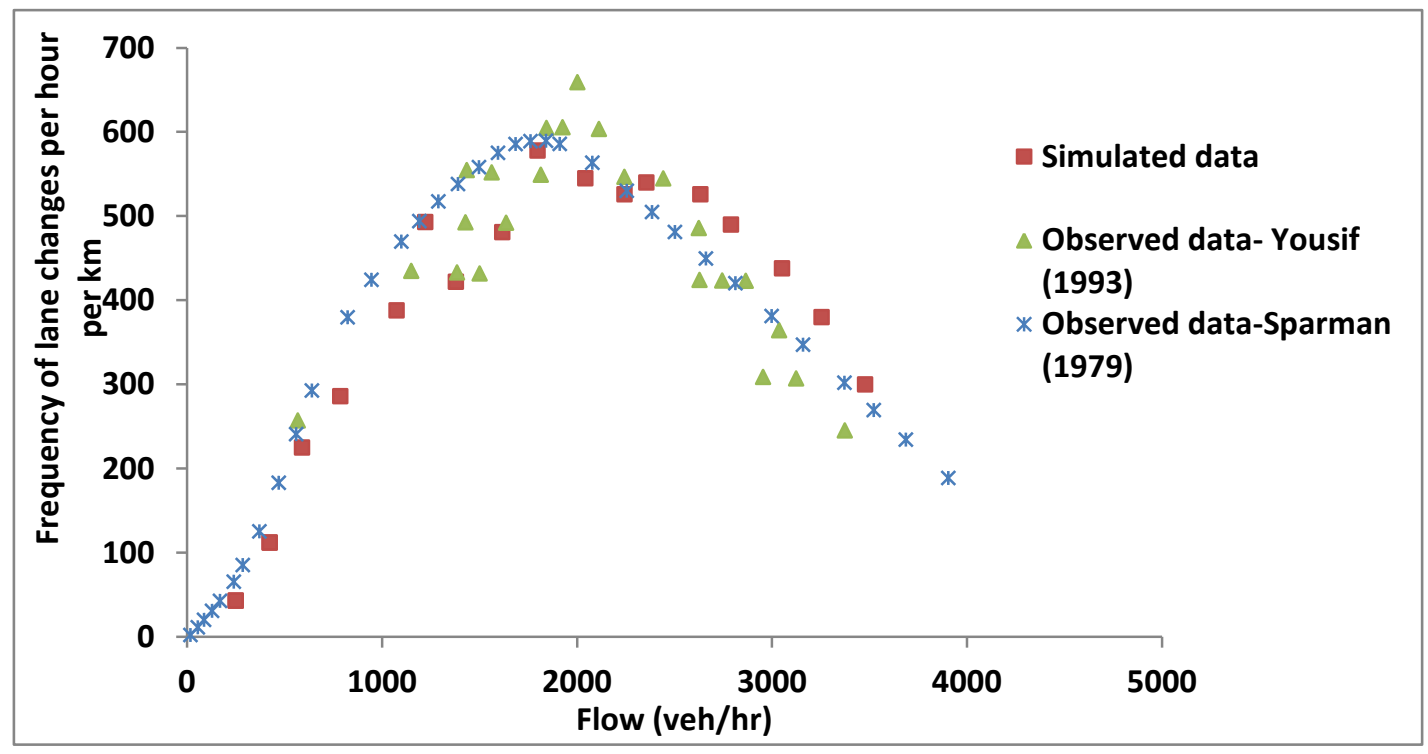

Fig. (6): FLC from simulation compared with different sets of field data for two-lane normal sections.

The gap acceptance parameters $\left(\beta_{1}=0.5, \beta_{2}=0.6\right.$, $\beta_{3}=0.5, \beta_{4}=0.8$ ) have been obtained from the calibration process for both lead and lag gaps as indicated in Equations 1 and 2. The value for LD and LG must be equal or more than zero.

$$
\begin{aligned}
& \mathbf{L D}=\boldsymbol{\beta 1}\left[\frac{V L^{2}}{M P L}-\frac{V C^{2}}{M C}\right]+\beta 2 * \mathrm{RT} * V C \\
& \mathbf{L G}=\boldsymbol{\beta} 3\left[\frac{V C^{2}}{M C}-\frac{V F^{2}}{M F}\right]+\beta 4 * \mathrm{RT} * V \boldsymbol{F}
\end{aligned}
$$

Where;

LD is the min. lead gap (m).

LG is the min. lag gap (m).

$\beta 1, \beta 2, \beta 3 \& \beta 4$ are calibration parameters.

$\mathrm{VL}$ is the speed of leading vehicle $(\mathrm{m} / \mathrm{sec})$.

$\mathrm{VC}$ is speed of lane changing vehicle $(\mathrm{m} / \mathrm{sec})$.

$\mathrm{VF}$ is speed of following vehicle $(\mathrm{m} / \mathrm{sec})$. 


\section{MPL is the maximum deceleration of the leading vehicle in the target lane $\left(\frac{\mathrm{m}}{\mathrm{sec}^{2}}\right)$}

$\mathrm{MC}$ is the maximum deceleration of the lane changing vehicle $\left(\frac{\mathrm{m}}{\mathrm{sec}^{2}}\right)$.

$\mathrm{MF}$ is the maximum deceleration of the following vehicle $\left(\frac{\mathrm{m}}{\mathrm{sec}^{2}}\right)$.

\subsection{Weaving rules}

The weaving section characterized by the interaction between traffic streams coming from the motorway with that coming from the on-ramp which is different from the interaction within motorway normal section. The last one is due to the cooperative behaviour (i.e. shifting to adjacent lanes or staying in the same lane but with applying deceleration). For the case of sections with onramps, the same behaviour conducted but without shifting to adjacent lane (in the case of one auxiliary lane).

Another important behaviour has been applied called close following. This phenomenon is represented by accepting small spacing between the changing vehicle and its leader (Wang, 2006). Then, the changing vehicle leaves the close following behaviour after finishing changing lane and returns to the normal case(i.e. the spacing gap increases to be as in the normal case) representing the relaxation behaviour (Laval and Leclerca, 2008 and Cohen, 2004). In this study, the duration of close following behaviour for weaving vehicles, was taken as $20 \mathrm{sec}$ (Cohen, 2004).

\subsection{Weaving behaviour}

To achieve the weaving process several complicated steps may be conducted such as reducing and increasing the speed of vehicles involved in the weaving process among merging and diverging vehicles as indicated in Figure 7. From field data collecting by current study from weaving sections, more than $90 \%$ of courtesy yielding behaviour was found. Whereas, the cooperative lane changing has been assumed for non-weaving vehicles when their decelerations are less or equal to $-3 \mathrm{~m} / \mathrm{sec}^{2}$. This value has been recognized as the maximum deceleration value which could be applied to drivers under normal conditions (ITE, 2010).

Al-Jameel (2011) suggested the effective length which is the length at which most weaving vehicles completed their manoeuvres. This length is affected by the geometric design such as weaving type and weaving length. According to Al-Jameel (2011), the effective length was about $200 \mathrm{~m}$ for ramp weaving sections as the weaving length was more than $300 \mathrm{~m}$, while this length represented the whole of the weaving length for sections with lengths less than $150 \mathrm{~m}$ for the same type. In this study, the effective length used instead of total weaving length to make a driver accepting high risk in terms of maximum deceleration. Other characteristics were also investigated such as volume ratio (VR) and weaving ratio $(\mathrm{R})$. The developed model is shown as in Figure 8.

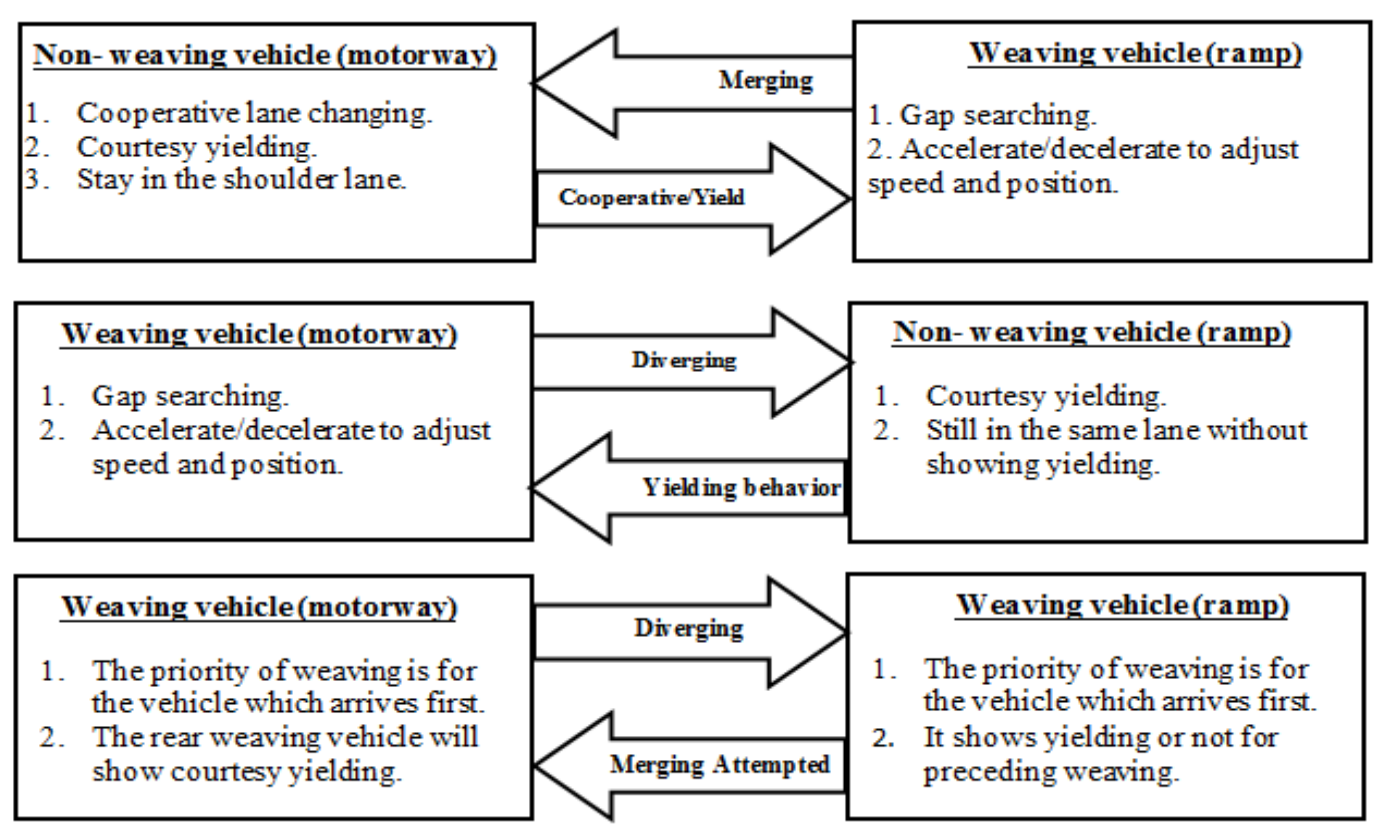

Fig. (7): Interaction behaviours for weaving vehicles (motorway and ramp). 


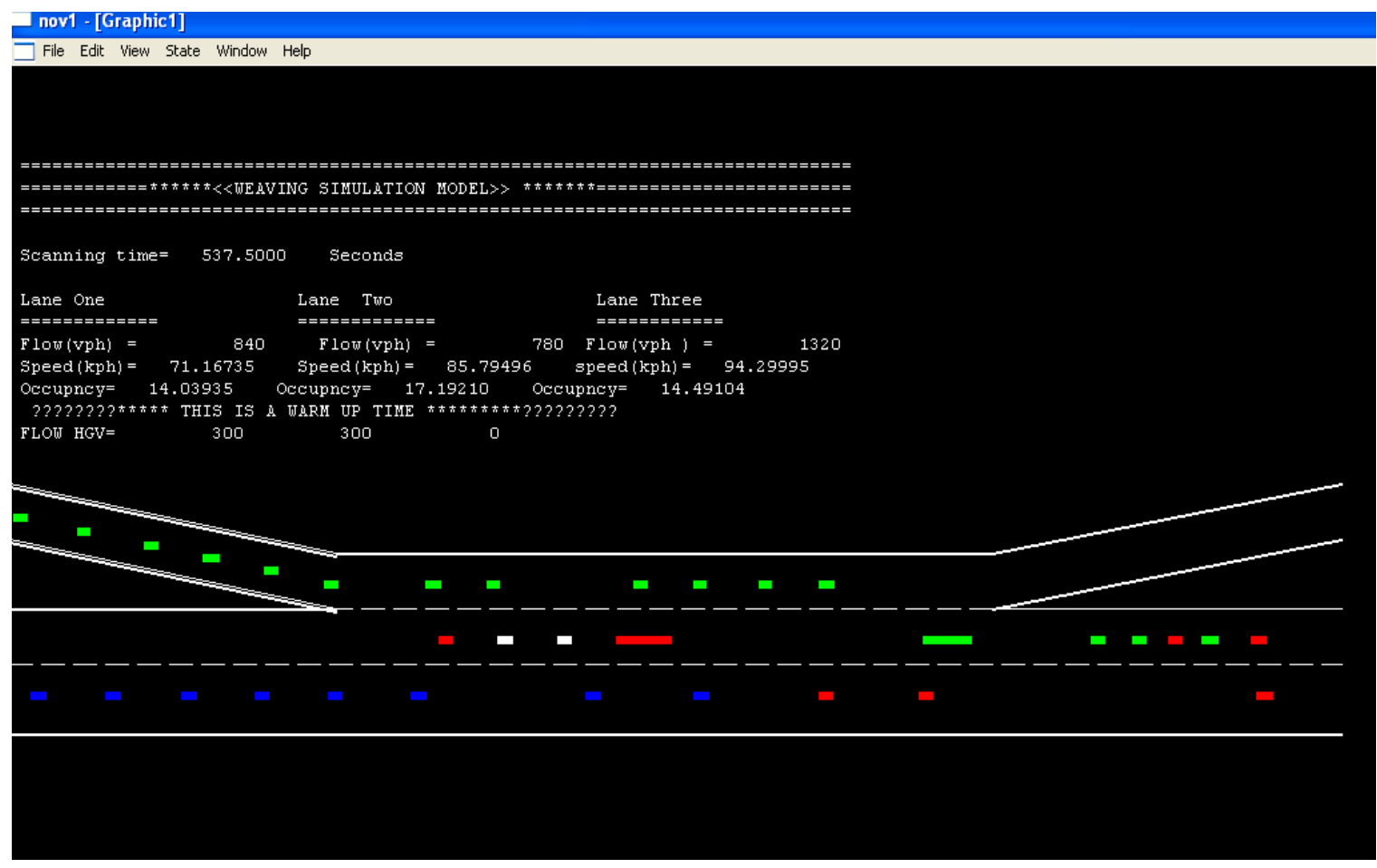

Fig. (8): The Developed model during this study.

6.5 Testing the developed model with field data

Field data from video recordings and data from the Motorway Incident Detection and Automatic Signalling (MIDAS) was used to test the developed model. Figure 9 demonstrates the location of loop detectors at the weaving section on the M60 J2. The upstream loop detector was used as input for the simulation model and other loops were used for comparison with field data.

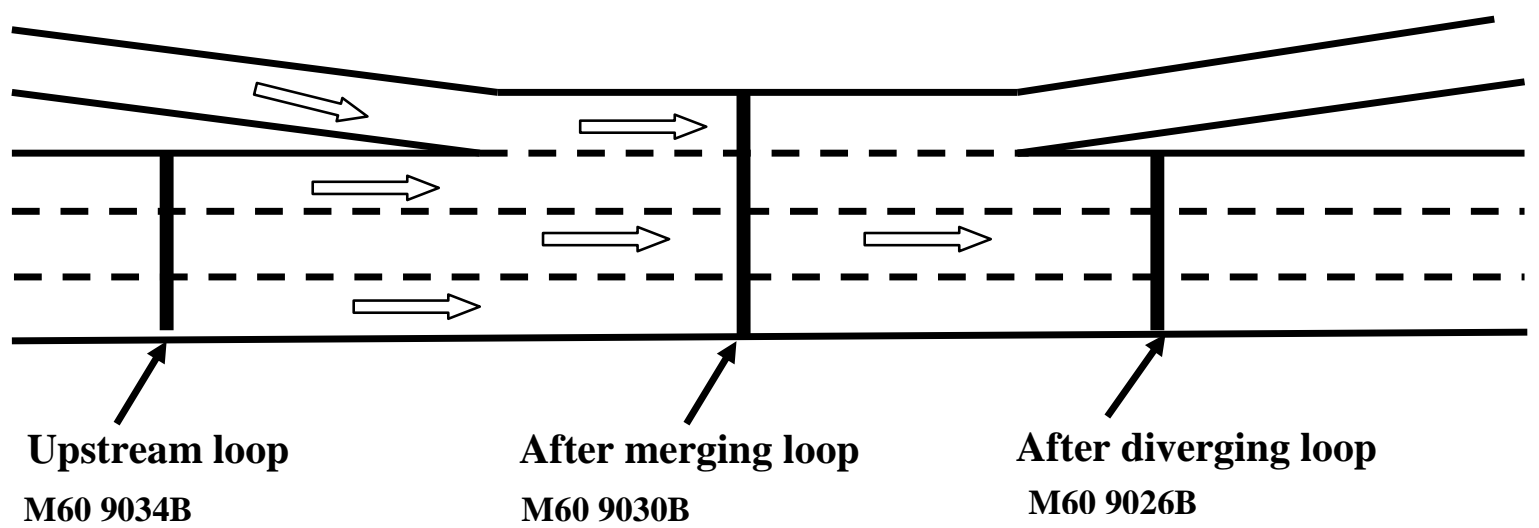

Fig. (9): Data collected from different loop detectors for the M60 J2 weaving section.

The type of this weaving section is Type A (ramp weave) with four lanes (i.e. the motorway consists of three lanes and one lane for the onramp). The length of the section is $400 \mathrm{~m}$ with four lane weaving section. This set represented 130 minutes of data for both speed and flow and was used to calibrate the developed model.

For this weaving section, there are three loop detectors, as follows: 
- the upstream detector (M609034B) at 200m from the entrance point,

- the merging detector (M609030B) at 200m after the entrance point, and

- the diverging detector (M609026B) at 90m after the exit point.

The optimum parameters for Equations 1 and 2 have been selected from the calibration process as $\left(\beta_{3}=0.3\right.$ and $\left.\beta_{4}=0.4\right)$. Figure 10 indicates clearly how simulated data try to capture field data and Table 4 shows the statistical tests for the same data. The statistical tests are the coefficient of correlation (r), root mean square percent (RMSP), Theil's inequality coefficient (U), Theil's mean difference (Um) and Theil's standard deviation (Us). These tests have been adopted by different traffic simulation models (Hourdakis et al., 2003 and Wang, 2006). The results of the comparison indicate that these values are within acceptable limits. Therefore, the developed model reasonable mimics the reality as indicated in Table 4.

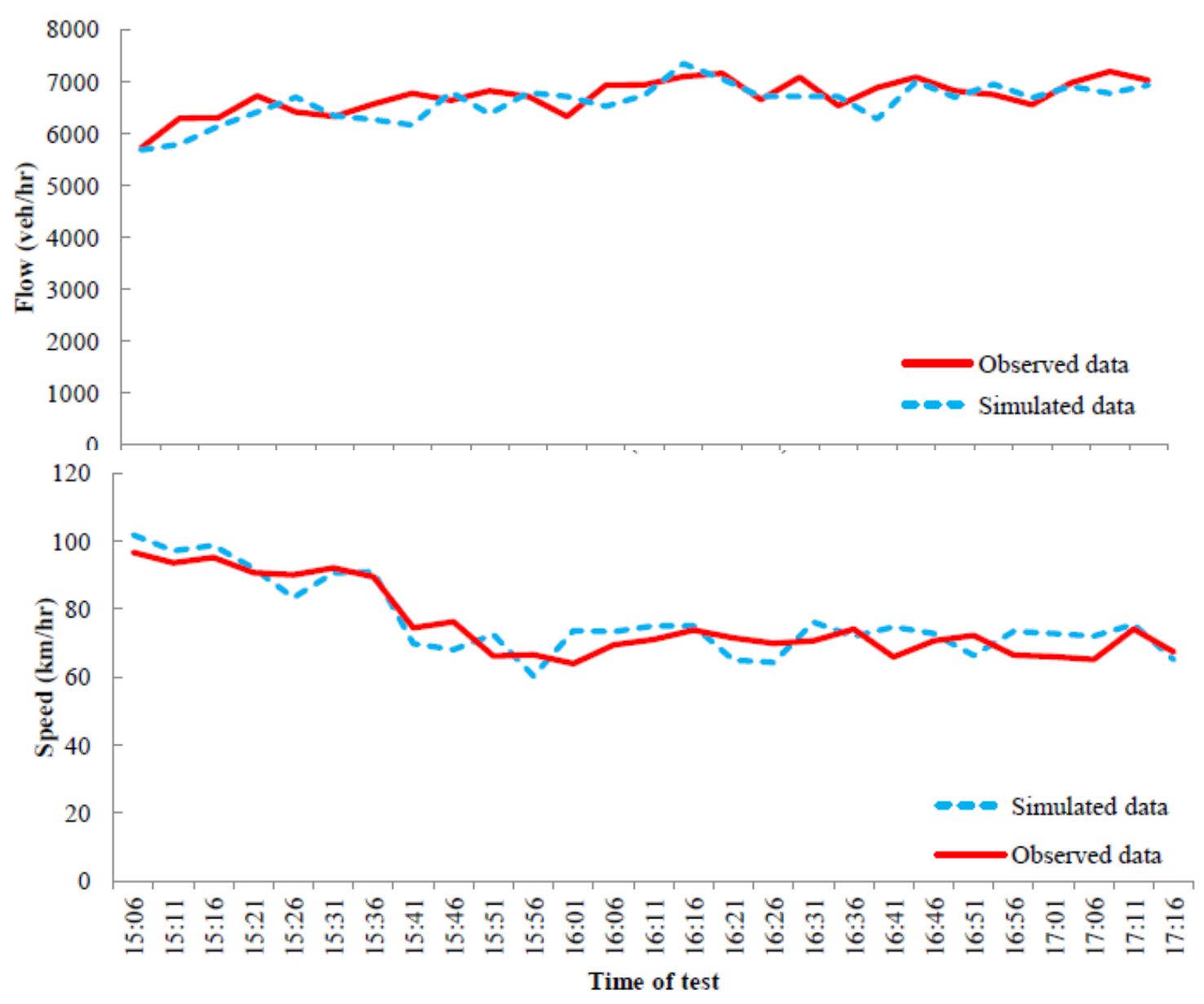

Fig. (10): Comparison between field and simulated data.

Table (4): Validation of the developed model with data from the M60-J2 (11/05/2011).

\begin{tabular}{ccc}
\hline Location & & After merging section \\
\hline Parameters & Flow & Speed \\
\hline$r$ & 0.97 & 0.87 \\
\hline$U$ & 0.0169 & 0.0236 \\
\hline Um & 0.00022 & 0.24 \\
\hline Us & 0.043 & 0.24 \\
\hline RMSP\% & 2.7 & 7.3 \\
\hline
\end{tabular}




\section{Application of the develped model}

As observed on site, that the main problem was that the diverging vehicles changed lanes earlier and very close to the entrance point due to very low flow in the on-ramp lane. Such behaviours are supported by Lee and Cassidy (2009).

Figure 11 shows both the original case (A) and the improved case (B). The improved process can be summarised by adding a solid line beside the old broken one to prevent diverging vehicles from changing lane along the first $150 \mathrm{~m}$ and at the same time to allow the merging vehicles to change lane. In addition, the broken line close to the exit point has been deleted for a distance of about $90 \mathrm{~m}$ before the exit point. By doing this, the type of weaving section has been changed from ramp weave (Type A) to Type B as shown in Figure 11. The developed model was then used to test this scenario. The same flow data from the field that caused the bottleneck was used as inputs to the model. The results show increase in the level of speeds at a simulated loop detector located at $200 \mathrm{~m}$ from the entrance point for the new configuration. This was more effective than the previous (original case) as shown in Figure 12. Moreover, there were no queues at or close to the entrance point.

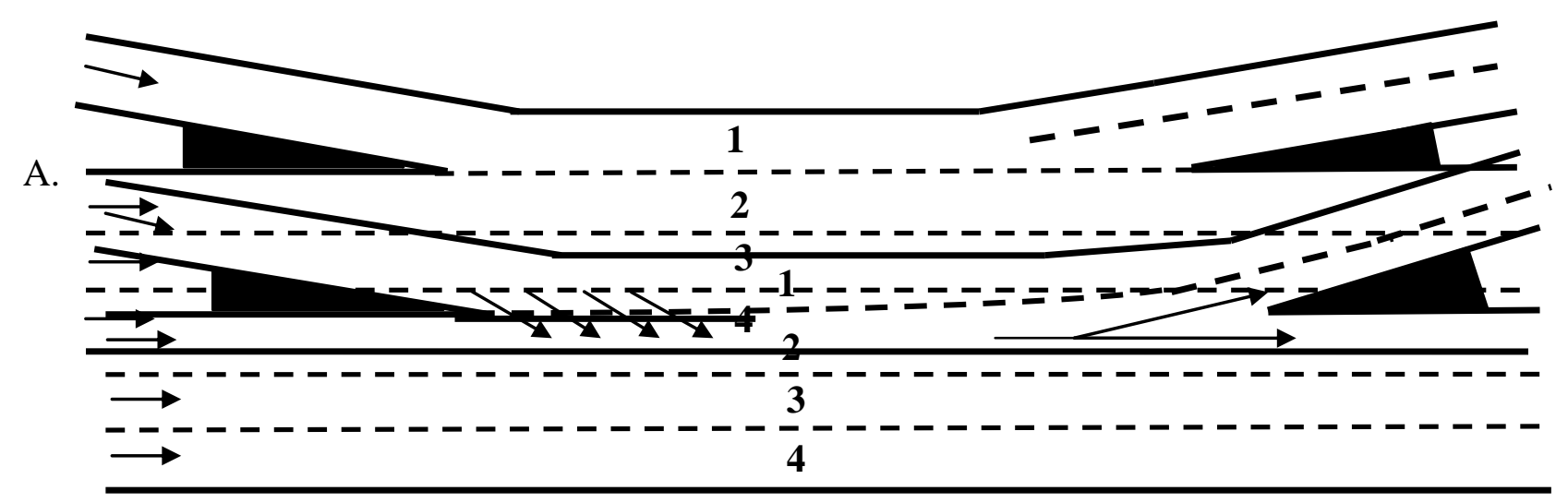

Original case (Sketch).

B. Improvement case (Sketch).

Fig. (11): Comparison between new and old configurations (Northenden Site 1). 


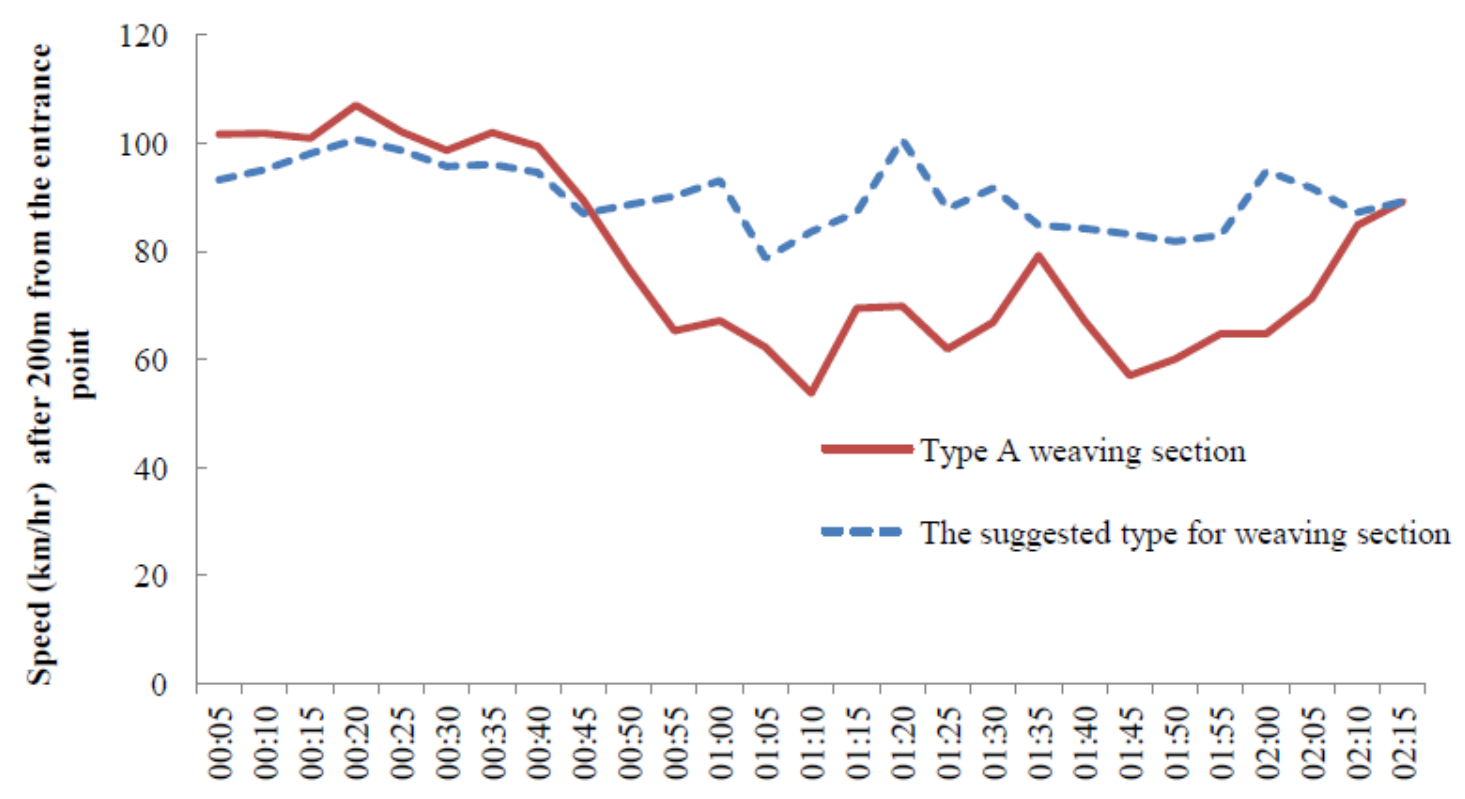

Time interval for simulated model

Fig. (12): Comparison between speeds for new and old weaving section configurations.

It is worth mentioning here that the capacity of Type $\mathrm{B}$ weaving section for a certain number of lanes and traffic characteristics is higher than the capacity of Type A for the same characteristics (see Exhibit 24-8-HCM 2000). Moreover, Stewart et al. (1996) used INTEGRATION to evaluate the capacity of weaving sections. The results show that the capacity of Type $\mathrm{B}$ weaving sections is higher than both Types $\mathrm{A}$ and $\mathrm{C}$ for the same characteristics. This is because Type $\mathrm{B}$ is less affected by the VR because of the small number of lane changes in this type of section.

\section{CONCLUSIONS}

The main findings and conclusions from this study can be summarised as follows:

1. A new parameter was introduced in this study which is the effective length. This factor was investigated for seven sites of weaving sections. It was found that the effective length is the total weaving length when the actual weaving length is less than $300 \mathrm{~m}$ for ramp weave section. For the same type of weaving section, it was found that the effective length is only $200 \mathrm{~m}$ even if the actual weaving length is higher than $300 \mathrm{~m}$.

2. A segregation factor was analysed for two weaving sections of different configurations, Type $A$ and $C$. This revealed that the first $250 \mathrm{~m}$ upstream of weaving section represents $70 \%$ of all segregation for the weaving traffic.
3. The analysis of the weaving data and field observations shows that bottlenecks start in the first $70 \mathrm{~m}$ from the first part of the weaving section and then propagate to the upstream section of the entrance area. Therefore, the potential location of the bottleneck is within the first $70 \mathrm{~m}$ from the entrance point of a weaving section and the upstream section of a motorway which is extended for more than $200 \mathrm{~m}$ from the entrance point.

4. Based on the field data from the investigated weaving sites, the value of VR that triggers a bottleneck in the ramp weaving section (Type A) with four lanes is less than the value reported by the HCM.

5. New weaving characteristics were investigated from field data called the merging and diverging points. These points show the locations for the concentration of merging/diverging vehicles along the weaving section. These points could be used as a validation factor for the developed model with field data.

6. According to the developed model, the effect of the actual weaving length was found to be very effective for a certain length of each type of weaving section and after that limit its effect vanished. For this study, just ramp weaving sections were investigated with two, three and four lanes.

7. A new management scenario was adopted for the first time. This management scenario can be summarised by changing the type of a weaving 
section from Type A to Type B. This scenarioHCM (2000). Highway Capacity Manual. Transportation could be achieved just by using pavement Research Board, TRB Special Report 209, USA. markings. This managed scenario provides moreHourdakis, J., Michalopoulos, P., and Kottommannil, efficiency and capacity of the changed section. J.(2003). Practical Procedure for Calibrating The effectiveness of this scenario not only be Microscopic Traffic Simulation Models. proved by the developed model in terms of Transportation Research Record, 1852, pp.130-139. increasing the level of speed and flow but also byInstitute of Transportation Engineering, ITE. (2010). Traffic other methods such as the HCM. This Engineering Handbook. $6^{\text {th }}$ Edition, USA: Washington. management plan could bring more suitable andKwon, E., Lau, R., and Aswegan, J. (2000). Maximum effective solutions for several cases with similar Possible Weaving Volume for Effective Operations of conditions as those on the Northenden Site 1. This Ramp-Weave Areas-Online Estimation. Transportation solution may be more economical than others such Research Record, (1727), pp.132-141.

as using ramp metering and adding other sets efLaval, J., and Leclercq, L. (2008). Microscopic modelling of loop detectors. Finally, this management does not the relaxation phenomenon using a macroscopic laneneed any further test to prove its efficiency changing model. Transportation Research $B, 42(6)$, because the operational characteristics of Type B pp.511-522.

is better than Type A in terms of carrying moreLee, J., and Cassidy, M. (2009). An Empirical and VR than Type A as mentioned in the HCM 2000. Theoretical Study of Freeway Weave Bottlenecks.

\section{REFERENCES}

- Al-Jameel, H. (2009). Examining and Improving the Limitations of the Gazis-Herman-Rothery Carfollowing Model. In: Salford Postgraduate Annual Research Conference (SPARC), $8^{\text {th }}-9^{\text {th }}$ May 2009,Pan University of Salford, UK.

- Al-Jameel, H. (2010). Evaluation of Car-following Models Using Field Data. In: Salford Postgraduate Annual Research Conference (SPARC), $10^{\text {th }}-11^{\text {th }}$ June 2010,Pig University of Salford, UK.

- Al-Jameel, H. (2011). Developing a Simulation Model to Evaluate the Capacity of Weaving Section. UniversitySpar of Salford, UK.

- Bertini, R., and Malik, S. (2004). Observed Dynamic Traffic Features on a Freeway Section with Merges andSulta Diverges. Transportation Research Record (1867), pp. 25-35.

- Cohen, S. (2004). Application of Relaxation Procedure ferVer Lane Changing in Microscopic Simulation Models. Journal of the Transportation Research Board, (1983), pp.50-58.

- Design Manual for Roads and bridges. (2010). The Highway Agency, Scottish Executive, Welish Assembly Government and the Department for regional Northern Ireland.

\section{-}

- Fazio, J., and Rouphail, N. (1990). Conflict Simulation in INTRAS: Application to Weaving Area Capacity Analysis. Transportation Research Record, (1287), pp. $96-107$.

- Fredericksen,V., and Ogden, M. (1994). Proposed Analytical Technique for Analysing Type A Weaving Sections on Frontage Roads. Transportation Research Record, (1457), pp.50-58. Theoretical Study of Freeway Weave Bottlenecks.
California PATH Research Report, UCB-ITS, PRR-13. Lertworawanich, P., and Elefteriadou, L. (2003). Methodology for Estimating Capacity at Ramp Weaves Based on Gap Acceptance and Linear Optimization. Transportation Research Record B, (37), pp.459-483.

nwai, S., and Dia, H. (2005). A Reactive Agent-Based Neural Network Car Following Model. IEEE, Conference on Intelligent Transportation Systems, pp.326-331.

gnataro, L., McShane, M., and Roess, S. (1975). Weaving Area-Design and Analysis. NCHRP Report 195, New York: Polytechnic Institute of New York.

rmann, I., (1979). The Importance of Lane-changing on Motorway. Traffic Engineering + Control, (20), pp.320323.

an B., and McDonald, M. (2001). The lane changing process: Data analysis and modelling behaviour. Traffic Engineering + Control, 43(5), pp.202- 207.

mijs, R., and Schuurman,H. (1994). Evaluating Capacity of Freeway Weaving Section and On-ramps Using the Microscopic Simulation Model FOSIM. Proceeding of the $2^{\text {nd }}$ International Symposium on Highway Capacity, (2), pp.651-670.

Wang, J. (2006). A Merging Model for Motorway. (PhD Thesis), University of Leeds, Leeds.

Yousif, S. (1993). Effect of Lane Changing on Traffic Operation for Dual Carriageway Roads with Roadworks. ( $\mathrm{PhD}$ Thesis), University of Wales, Cardiff.

-Zarean, M., and Nemeth, Z. (1988). WEAVSIM: A Microscopic Simulation Model of Freeway Weaving Sections. Transportation Research Record, (1194), pp.48-54. 